\title{
Digitalization and financial performance of enterprises from the livestock sector
}

\author{
Dimitrina Stoyancheva ${ }^{1 *}$, and Rumyana Angelova ${ }^{1}$ \\ ${ }^{1}$ Department of Industrial Business and Entrepreneurship, Trakia University, 6000 Student Campus, \\ Stara Zagora, Bulgaria
}

\begin{abstract}
The European Union's strategy for the digitalization of agriculture is reflected in several initiatives, programs, and projects. The effect of promoting the application of digital technologies is expected to result in an increase in the competitiveness of farmers and their entry into the world market. This is expected to be done through the introduction of innovations leading to cost optimization and greater efficiency. The article examines some concepts related to digitalization, such as "digital maturity", "digital transformation", "digital intelligence" and others. A Probit model is used to study the relation of digitalization and the firm performance of entrepreneurs in the livestock sector. Based on an empirical study of the livestock farms, the relationship between digitalization and financial results, sales revenue, size, and innovation activity is analyzed. Our findings show that as the return on assets increases, the probability of livestock farms implementing digital solutions increases. A negative relationship between the intensity of innovation spending and the propensity for digitalization is proved. As the size of their assets increases, companies are more likely to implement digital solutions.
\end{abstract}

\section{Introduction}

Increasing business performance and competitiveness are one of the main goals of enterprises. In the era of digital transformation, the introduction of digital solutions is considered a key factor for its achievement. In the economic literature, the relationship between financial performance and financial sustainability, and digitalization is widely discussed. Many studies confirm the positive effect of the introduction of digital solutions in the business [1-3]. Other authors prove ambiguous dependence [4].

The present study initially examines some concepts related to digitalization, such as "digital maturity", "digital transformation", "digital intelligence" and others.

Digitization, digitalization, digital transformation, and digital maturity

The terms "digitization" and "digitalization" are becoming more commonplace and are increasingly being used interchangeably. The definition of "digitization"/digitalization" given by the online Oxford Learner's Dictionaries is that it is "the process of changing data into a digital form that can be easily read and processed by a computer". For this purpose,

\footnotetext{
*Corresponding author: dimitirna.stoyancheva@trakia-uni.bg
} 
the information is encoded using the symbols 1 and 0 in a form convenient for computer processing.

Digital transformation is associated with automation and is the integration of digital technologies in business processes, in a way that provides faster and better customer service [5]. Automation, on the other hand, presupposes the performance of tasks through the absence or minimal intervention of the human factor. Fitzgerald et al define digital transformation as " the use of new digital technologies (social media, mobile, analytics or embedded devices) to enable major business improvements (such as enhancing customer experience, streamlining operations or creating new business models)" [6]. Information about new products or services reaches customers faster, the purchase of the same can be done remotely through distance trading platforms, etc. The operational process of supply can be carried out at any time and from anywhere in the world, by ensuring transparency in the terms of delivery. Communication within the enterprise is improved and labor productivity is increased by automating operational processes. The impact of digital transformation can be sought in both economic and social, and environmental aspects [7], and in addition to operational efficiency, a direct consequence of it is the improvement of enterprise sustainability.

The digital transformation is most often carried out through the use of cloud technologies, mobile devices, large databases, social media, and more.

Cloud technologies involve storing information on servers that are located remotely and offer shared storage conditions. Their use leads to a reduction in the cost of storing information, greater security for its protection from malicious external influences, and immediate access, if necessary. Cloud technologies require minimal investment and quick access to stored information at all times. Mell and Grance define the cloud technology as a "model for enabling ubiquitous, convenient, on-demand network access to a shared pool of configurable computing resources (e.g., networks, servers, storage, applications, and services) that can be rapidly provisioned and released with minimal management effort or service provider interaction" [8].

Mobile devices include laptops, tablets, media players for games, smartphones, smartwatches, e-book readers, and more. They are considered to be the first tool people use when searching for information on health sites, real estate, administrative and banking services, job searches, etc. According to data of the Statistical Institute (NSI) in Bulgaria, in 2019 , the persons using a mobile phone or smartphone are $63.2 \%$ of the population, compared to $23.10 \%$ in 2014 .

Large database analysis tools allow the assimilation and retrieval of intelligent information from large volumes of diverse data at very high speeds. The main features of large databases are information, technology, methods, and impact. De Mauro et. al gives the following definition of Large Databases: " Big Data is the Information asset characterized by such a High Volume, Velocity, and Variety to require specific Technology and Analytical Methods for its transformation into Value" [9]. The management of large databases goes through several stages: data collection, storage, processing, and analysis [7].

Social media are systems that facilitate social contacts through computers [10]. Because man is a social being, by those modern means of communication, information is disseminated among social groups such as teams, communities, organizations, and markets. In addition, the information is not "anonymous", but relies on the connection of some people who in turn are connected to other people. Examples of social media are e-mail and social networks such as Facebook, Twitter, Linked In, etc. The focus of social media is aimed at increasing the exchange of information between people, seeking the effect of understanding, commitment and influence, and is particularly suitable for customer-oriented industries such as retail, banking, etc. 
The use of digital technologies is directly dependent on the digital maturity of the company. Achieving digital maturity occurs gradually over time. Different companies have different degrees of digital maturity, and there is always a way for a company to continue to grow and adapt, i.e. the process of maturity can always be continued [11]. Determining the digital maturity of the company comes down not only to the analysis of the technologies used by it but also to the readiness and ability of the staff to adapt to them. Investing large sums of money in digital technologies is not a sufficient condition for a company to declare itself digitally mature. Its staff needs to be trained and work with them.

\section{Digitization and financial sustainability}

Financial sustainability is an economic category that expresses the balance between the internal characteristics of the enterprise and the external, surrounding environment [12-13]. It is a prerequisite for the implementation of innovations and a consequence of successfully implemented innovation processes, the results of which are expressed in increasing economic profitability. It assumes a financial balance not only at a certain date but also its maintenance for a long future period [14]. Financial sustainability is essential for planning the future development of the company in an aggressive environment [15].

The impact of digitalization on firm performance has been the subject of many scientific studies. The emphasis is on better firm performance as a result of intensive digital transformation.

The digital transformation has an impact on company results such as:

- Companies with a higher level of digital maturity are more likely to invest in training to improve the digital skills of their staff [16].

- Companies with a higher level of digital intelligence have better financial results [17] and generate more revenue from their available assets [18];

Table 1 lists commonly used indicators for measuring firm performance in the literature.

Table 1. Indicators for measuring firm performance in the literature

\begin{tabular}{|c|c|}
\hline Sources of information & Indicators \\
\hline Bellakhal, R., R. Mouelhi - & Sales volume; \\
Sales growth; \\
Digitalization and Firm Performance: & Internationalization (export) \\
Evidence from Tunisian SMEs [1] & Leverage \\
\hline Muhammad Kamran Khan, Mohammad & Total liquidity; \\
Nouman Muhammad Imran Khan. & assets; \\
Determinants of Financial Performance of & Size of the company - based on the value of \\
Financial Sectors (An Assessment through & Risk = (EBIT / Earning after interest and Tax) \\
Economic Value Added) [15]. & Return on Assets; \\
\hline Burca, Ana-Maria, Gh.Batrinca, The & Leverage; \\
Determinants of Financial Performance in the & Size of the company; \\
Romanian Insurance Market [13] & Age of the company; \\
& Equity; \\
& Market share; \\
& Share of investments; \\
& Diversification; \\
& Solvency \\
\hline Kurtz, H., A. Hanelt, S. Firk, Digital Business & Size of the company; \\
Strategy and Firm Performance: An & Net sales revenue; \\
Empirical Investigation [4] & Leverage; \\
& Total liquidity; \\
& Profitability based on net sales revenues; \\
& Ratio of R\&D expenditure to net sales revenue \\
& Revenue efficiency ratio; \\
& \\
&
\end{tabular}


Capital intensity - the ratio between the assets of the enterprise to the number of staff

Net sales revenue; Leverage;

Profitability based on net sales revenues; Total liquidity;

Ratio of R\&D expenditure to net sales revenue Revenue efficiency ratio;

Capital intensity - the ratio between the assets of the enterprise to the number of staff.

\section{Data and methodology}

\section{Empirical model}

The purpose of the empirical study is to study a relationship between the probability of livestock farms using digital solutions and the achieved profitability and innovation activity. We evaluate the factors that determine the propensity of livestock farms to seek and implement digital solutions in their production activities.

In the current study we put the following hypothesis: The probability of livestock farms to use digital solutions in their activities depends on the achieved profitability and innovation activity.

Because the study contains a dependent variable that cannot be directly observed, i.e. a latent variable, a proper regression model for estimating the relationship between the propensity to digitize and the selected explanatory variables (financial performance indicators and company characteristics) is the Probit model.

Probit model is a binary response model of the form [19, p. 482]:

$$
P\left(y=1 \mid \mathrm{x}_{i t}\right)=G\left(\mathrm{x}_{i t} \beta\right) t=1,2,3 \ldots T
$$

where $\mathrm{G}$ is a function taking on values between 0 and 1 , that is: $0<G(z)<1$, for all real numbers $z$. Thus the "estimated response probabilities are strictly between zero and one" [19].

In the present study, we introduce a dependent variable, Yi, with dichotomous outcome that is defined as followed:

$$
Y_{i}=\left\{\begin{array}{r}
1, \text { if } Y^{*} \text { digitalization } \\
0, \text { if } Y^{*} \text { no digitalization }
\end{array}\right.
$$

where the observed Yi takes the two outcomes - presence or absence of digitalization, and $\mathrm{Y}^{*}$ is the hidden (latent) variable and expresses the probability that livestock farms will implement digital solutions in their activities.

For the purposes of the study, the following Probit model was estimated:

$$
\begin{gathered}
P\left(Y=1 \mid \text { ROA }_{i t}, \text { RDInt }_{i t}, \text { SalesGrowth }_{i t} \text {, Leverage }_{i t}, \text { LnTA }_{i t}, \text { LNAge }=P\left(\beta_{0}+\beta_{1} \text { ROA }_{i t}+\right.\right. \\
\left.\beta_{2} \text { RDInt }_{i t}+\beta_{3} \text { SalesGrowth }_{i t}+\beta_{4} \text { Leverage }_{i t}+\beta_{5} \text { LnT }_{i t}+\beta_{6} \text { LNAge }+\epsilon_{i t}>0\right)=\Phi\left(\beta_{0}+\right. \\
\beta_{1} \text { ROA }_{i t}+\beta_{2} \text { RDInt }_{i t}+\beta_{3} \text { SalesGrowth }_{i t}+\beta_{4} \text { Leverage }_{i t}+\beta_{5} \text { LnT }_{i t}+\beta_{6} \text { LnAge }_{i t}
\end{gathered}
$$

where:

$\mathrm{y}$ - the probability livestock farm i to apply digital solutions i year t; 
The betas, $\beta$ s are the coefficients to be estimated, and the $\mathrm{X}$ is a vector of independent variables - return on assets (ROA), Research and Development activity (RDInt), the growth of sales (SalesGrowth), Leverage, farm size (LnTA) and age (LnAge) of the i-th livestock farm.

\section{Variables}

The dependent variable in the model is the presence/absence of digitalization of the livestock farms. As a basis for determining the existence of digitalization, we use the NSI methodology for the use of information and communication technologies and e-commerce in enterprises for 2020. [20] Enterprises in the agricultural sector are not monitored by the NSI, therefore we obtained the necessary data for the survey through publicly available information. We assume that livestock farms use digital solutions for their activities when the following conditions are simultaneously met: 1) they have a website; 2) make sales through websites or e-commerce applications (web sales); 3) issue electronic invoices in a standardized format; 4) make sales of the EDI type.

\section{Independent variables:}

The choice of all variables in the model is based on the dependent and control variables widely used in the economic literature, following the literature summarized in the previous section.

The annual return on assets, measured as the ratio of net profit to total assets of the enterprise, ROA is a widely used indicator to measure the farms' efficiency with the assets used.

Through the indicator of the intensity of intangible assets, we estimate what part of livestock farms' revenues in the current year they invest in innovation activities. We calculate the intensity of intangible assets as a ratio of the sum of the costs of intangible assets and the net sales revenue.

We use the variable sales growth, measured as the growth rate of sales revenue, to track the relationship between the percentage change in revenue and the results of enterprises.

As an indicator of the differences in the capital structure of enterprises, we use the variable leverage, calculated as the ratio of the total amount of liabilities and the number of assets. The high level of debt in the capital structure is often seen as a preceding shrinking of the opportunities for firms' external financing and as a consequence of reducing their profitability and investment, including innovation activity.

We calculate the size of enterprises (size) as a natural logarithm of the total amount of assets.

The variable age of enterprises (age) is indicative of the years of activity of livestock farms from the date of their establishment and is presented in the model by a natural logarithm of the number of years of activity.

For the analysis we use panel data, which provides us with the necessary financial information on balance data for the financial results, net income, expenses, liabilities, number of employees, and total assets of enterprises for a period of 5 years. The panel data allows us to analyze and evaluate their variation in 2 directions. The first one is at the farm level so that we can track the change in returns over the study period. Secondly, it is appropriate to look for effects at the level of annual (aggregate) values between farms. We assume that livestock farms have specific, individual characteristics that also affect the likelihood of implementing digital solutions in their business. Such characteristics are, for example, the competence of the management and employees in the enterprises, the access to various information, individual qualities and skills, etc., the influence of which is independent of the effects of the factors applied in the model. 


\section{Data}

The sample size consists of 81 livestock farms operating in the field of animal husbandry, for which financial data have been collected. The data are used to calculate financial sustainability indicators. An attempt has been made for all farms to trace the existence of activities indicating a process of digital transformation. The sample is composed of small, medium, and large enterprises, in sector A "Agriculture, forestry, and fisheries", group 01.4 Livestock according to NACE Rev.2. The survey covers 5 years from 2015 to 2019.

According to the data, livestock farms, which recognize digitalization as an important factor in obtaining better economic performance, represent $26 \%$ of the total farms in the sample.

Differences in economic performance can be traced in Table 2. Livestock farms having digital activity are larger compared to non-digital active farms and provide significantly higher employment, realize higher incomes per employee, and pay higher wages. (Table 2).

Table. 2. Livestock farm performance in terms of digitalization

\begin{tabular}{|c|c|c|c|c|c|}
\hline Digitalization* & $\begin{array}{c}\text { Net income } \\
\text { per employee }\end{array}$ & $\begin{array}{c}\text { Personnel } \\
\text { Costs }\end{array}$ & $\begin{array}{c}\text { Non-current } \\
\text { assets }\end{array}$ & Total assets & $\begin{array}{c}\text { Employees (average } \\
\text { annual number) }\end{array}$ \\
\hline 0 & 103.7844 & 12.11997 & 13.38983 & 8604.949 & 46.285 \\
\hline 1 & 187.7519 & 16.58709 & 26.52381 & 16475.9 & 86.97619 \\
\hline
\end{tabular}

*Livestock farms adoption of digital solutions $(1=$ Yes, $0=\mathrm{No})$; Net income per employee, personnel costs, non-current assets, and total assets are presented in thousand leva.

** Differences are statistically significant at $\alpha=0,05$

Descriptive statistics of the variables

Tables 3 and 4 present the descriptive characteristic of the data and Pearson correlation values of the variables used in the model.

Table 3. Descriptive statistics of variables

\begin{tabular}{|c|c|c|c|c|c|}
\hline Variable & Obs. & Mean & Std. Dev. & Min & Max \\
\hline Digitalization & 405 & .3111111 & .4635207 & 0 & 1 \\
\hline ROA & 343 & .0898191 & .0899671 & 0 & .6326531 \\
\hline growth_sales & 405 & .3108916 & 5.607893 & -.9807692 & 112.75 \\
\hline leverage & 379 & 1.639358 & 5.60527 & 0 & 92.68182 \\
\hline rd_int & 398 & .0040947 & .0165336 & 0 & .1633848 \\
\hline In_TA & 400 & 8.61098 & 1.189101 & 3.713572 & 10.99045 \\
\hline In_age & 405 & 2.906132 & .2792288 & 2.079442 & 3.401197 \\
\hline
\end{tabular}

According to the data obtained, the average return on assets of companies implementing digital solutions is $9 \%$, and investments in intangible assets related to net income are on average $0.4 \%$. There is a very low rate of investment of livestock farms' revenues into innovation activities. The relative share of total liabilities is on average $1.64 \%$. The average growth rate of sales revenue is 0.31 .

The correlation matrix (Table 4) shows that there is no significant relationship between the variables studied.

Table 4. Correlation coefficients (Pearson Correlation)

\begin{tabular}{|l|l|l|c|l|l|l|l|}
\hline & Digitalization & ROA & $\begin{array}{c}\text { Growth } \\
\text { sales }\end{array}$ & leverage & rd_int & log_TA & log_age \\
\hline
\end{tabular}




\begin{tabular}{|c|c|c|c|c|c|c|c|}
\hline Digitalization & 1.0000 & & & & & & \\
\hline ROA & 0.3085 & 1.0000 & & & & & \\
\hline growth_sales & -0.0306 & -0.0480 & 1.0000 & & & & \\
\hline leverage & -0.0982 & -0.1564 & 0.0046 & 1.0000 & & & \\
\hline rd_int & -0.1364 & -0.0849 & -0.0150 & -0.0168 & 1.0000 & & \\
\hline Ln_TA & 0.3316 & 0.2058 & -0.0126 & -0.1376 & -0.0832 & 1.0000 & \\
\hline Ln_age & -0.0085 & 0.1335 & -0.0339 & -0.1796 & -0.0517 & 0.1936 & 1.0000 \\
\hline
\end{tabular}

\section{Results of the empirical study}

The results obtained from the Probit model with a dependent variable - digitalization are shown in Table 5.

Table 5. Results of the regression analysis

\begin{tabular}{|c|c|c|c|c|c|c|}
\hline Digitalization & Coef. & Std. Err. & $\mathbf{z}$ & $\mathbf{P}>\mathbf{z}$ & {$[\mathbf{9 5 \%}$ Conf. } & Interval] \\
\hline roa & 5.90285 & 1.638962 & 3.6 & $0.000^{*}$ & 2.690543 & 9.115157 \\
\hline growth_sales & -.5347001 & .496925 & -1.08 & 0.282 & 1.508655 & .439255 \\
\hline leverage & -.0777438 & .0931716 & -0.83 & 0.404 & .2603568 & .1048691 \\
\hline rd_int & -124.1276 & 64.1406 & -1.94 & $0.053^{*}$ & 249.8409 & 1.585636 \\
\hline log_TA & .7413547 & .1993591 & 3.72 & $0.000^{*}$ & .350618 & 1.132091 \\
\hline log_age & -.4547579 & .6736087 & -0.68 & 0.500 & 1.775007 & .8654909 \\
\hline cons & -6.468299 & 2.610399 & -2.48 & 0.013 & 11.58459 & -1.352011 \\
\hline /lnsig2u & .49562 & .3910119 & & & .2707493 & 1.261989 \\
\hline sigma_u & 1.281216 & .2504855 & & & .8733886 & 1.879479 \\
\hline rho & .6214295 & .0919875 & & & .4327232 & .7793684 \\
\hline LR test of rho=0: & chibar2(01) & $=49.52$ & & Prob & $>=$ chibar2 & $=0.000$ \\
\hline
\end{tabular}

Dependant variable: Digitalization: Livestock farms adopted digital solutions $(1=Y$ Yes, $0=N o$ ); Wald $\operatorname{chi} 2(6)=27.36$; Prob $>$ chi $2=0.0001$

*Significant at $5 \%$

Empirical results show that as the return on assets increases, the probability of livestock farms implementing digital solutions also increases. At the same time, Chen and Srinivasan (2020) prove that "declines in profit margins and sales growth after the firm engages in digital activity" [18]. We prove a negative relationship between the intensity of innovation spending and the propensity for digitalization. This result can be explained, among other reasons, by the type of intangible assets in which livestock farms invest. Investments in non-current assets mainly represent costs for concessions, patents, and trademarks (over $98 \%$ of the total costs for innovation), while the investments in R\&D have an insignificant relative share of less than $2 \%$ according to our sample. We observe a positive relationship between the size of livestock farms and their probability of digitalization. As the size of their assets increases, companies are more likely to implement digital solutions. It has been found that large agricultural enterprises follow a strategy of making high R\&D investments [21]. The obtained result contradicts the expectations of the enterprises, which are in the initial stage of the development of their activity, to be more inclined to digitalization. The average age of the livestock farm in the sample is about 20 years.

The results prove a significant role of the individual characteristics of livestock farms on probability to digitize. A high relative share of $62 \%$ of the unexplained dispersion of return on assets is due to specific factors arising from the individual livestock farm. 


\section{Conclusion}

Our country has set as a strategic goal the accelerated digitalization of Bulgarian agriculture and rural areas to achieve competitiveness in the sector, optimize production processes, increase incomes and yields of farmers, achieve sustainable bio-industry, and more.

The present study aims to better understand the relationship between the implementation of digital solutions by livestock enterprises and their business results, increasing sales revenue, size, and innovation activity.

A Probit model is applied to analyze the relationship between the probability of livestock farms to use digital solutions in their activities and the profitability and innovation activity. The results show that larger companies with a higher return on assets are more likely to implement digital solutions. At the same time, higher innovation activity does not increase the probability of digitalization.

The research leading to these results has received funding from the Ministry of education and science under the National science program INTELLIGENT ANIMAL HUSBANDRY, grant agreement $\mathrm{n}^{\circ}$ Д01-62/18.03.2021

\section{References}

1. R. Bellakhal, R.B.A. Mouelhi, EMNES Working Paper No 36, (2020)

2. L. A. Enríquez, H. Cuevas-Vargas, M.G. Adame, IRMBR, 4(3, part 2), 758-770 (2015)

3. R.A. Bahn, A.A.K. Yehya, R. Zurayk, Sustainability, 13(6), 3223 (2021)

4. H. Kurtz, A. Hanelt, S. Firk, Digital Business Strategy and Firm Performance: An Empirical Investigation, in: Wirtschaftsinformatik 2021 Proceedings 5 (Track 19) of The International Conference on Business Information Systems (WI 2021), 09-11 March 2021, the University of Duisburg-Essen, Germany (2021)

5. A. Hanelt, E. Piccinini, R.W. Gregory, B. Hildebrandt, L.M. Kolbe, Digital Transformation of Primarily Physical Industries - Exploring the Impact of Digital Trends on Business Models of Automobile Manufacturers, in Proceedings of 12th International Conference on Wirtschaftsinformatik (WI 2015), 4-6 March 2015, Osnabrück, Germany (2015)

6. M. Fitzgerald, N. Kruschwitz, D. Bonnet, M. Welch, Embracing Digital Technology, [Online], MIT SMR, 1-12 (2013)

7. V. Chandola, Digital Transformation and Sustainability, (Cambridge, Massachusetts, 2015)

8. P. Mell, T. Grance, NIST SP 800-145 (2011)

9. A. De Mauro, M. Greco, M. Grimaldi. Library Review, 65(3), 122 - 135 (2016)

10. The Encyclopedia of Human-Computer Interaction, 2nd ed, Interaction Design Foundation

11. G. Kane, D. Palmer, A.N. Phillips, D. Kiron, N. Buckley, Strategy, not Technology, Drives Digital Transformation, [Online], MIT SMR, (2015), [Accessed: 18 January 2018]

12. V. Kasarova, Modeli i pokazateli za analiz na finansovata ustoychivost na kompaniyata, (2010), Working Paper, NBU Scholar Electronic Repository (Unpublished), http://eprints.nbu.bg/637/

13. A.M. Burca, Gh. Batrinca, IJARAFMS, 4(1), 299-308 (2014)

14. M. Mihaylov, K. Mitov, R. Koleva, Analiz na industrialniya biznes, (Faber, 2013) 
15. M.K. Khan, M. Nouman, M.I. Khan, MPRA Paper No. 81659, (2015)

16. G.C. Kane, D. Palmer, A. Philips, D. Kiron, N. Buckley, Aligning the organization for its digital future, [Online], MIT SMR, 3-17 (2016)

17. W. Chen, S. Srinivasan, HBS Working Paper \#19-117, (2019)

18. Westerman, G., Tannou, M., Bonnet, D., Ferraris, P., and McAfee, A. (2012). The Digital Advantage: How digital leaders outperform their peers in every industry. MIT Center for Digital Business and Capgemini Consulting, pages 2-21.

19. J. Wooldridge, Econometric Analysis of Cross Section and Panel Data, (The MIT Press Cambridge, Massachusetts, London, England, 2002)

20. NSI, Questionnaire on ICT usage and e-commerce in enterprises, https://www.nsi.bg

21. R. Birner, T. Daum, C. Pray, Appl Econ Perspect Policy,1-26, (2021) 